\title{
Correlates of the Reading Interest of Chinese High School Students in International Schools
}

\author{
Wenji Dai ${ }^{1}$ \\ ${ }^{1}$ The University of Manila, Philippines \\ Correspondence: Wenji Dai, The University of Manila, Philippines. E-mail: 847572322@qq.com
}

Received: December 5, 2012

Accepted: January 15, 2013 Online Published: February 28, 2013

doi:10.5539/ass.v9n3p164

URL: http://dx.doi.org/10.5539/ass.v9n3p164

\begin{abstract}
Reading builds and shapes a man's life as part of the society he chooses to belong. It is an essential tool for learning especially for young students who should possess a level of interest in reading to enable them to understand and appreciate materials and tools for learning.

The study underscores the significance of reading interest in one's learning process and analyzes the different correlates that affect it and their extent. It brings to fore important features of independent and variable factors that function as correlates. To do this, a survey was conducted of a group of Chinese third year high school students in an international school in Makati City, Philippines.

On the independent factor, which is the personal profile of the respondents, the study involved more males than females. They are young and come from average income families. They belong to the average and high average students in their English classes. Majority prefer to join groups than be alone.

On the variables, which are the external factors, the data showed that parents and teachers influence them to a very great extent while classmates and friends affect them only to a great extent. Majority expressed that their home environment is generally conducive and reading materials are available.

In presenting its findings, the study finally attempts to show how they apply to our subject -- the Chinese high school students in international schools in general.
\end{abstract}

Keywords: reading, interest, personal characteristics

\section{The Problem and Its Background}

\subsection{Background of the Study}

The Singapore International School in Makati City, Philippines is an international school that adopts the Singaporean curriculum known for its strength in Mathematics and Science. They boast of a curriculum that is challenge driven, designed to develop positive attitudes and a level of thinking fit for globalization. They offer Pre-school, Primary and Secondary levels with a class size of 12 students to a teacher. Trilingual education is applied that includes British English, Mandarin and Filipino. The curriculum includes non-academic activities associated with arts and sports and a closely supervised "special time" allotted to finish school work and specific study areas that require special attention. They enforce a "no homework policy" to provide opportunities for family bonding at home.

Chinese students in the school compete with students of other nationalities -- Filipinos, Americans and Europeans. Survival at Singapore International School is a big challenge which can be made possible by a high level of interest and competence in reading. This paper shall attempt to assess the level of reading interest of the Chinese students and identify factors that will help upgrade and enhance it. This researcher as a fellow Chinese makes this objective a personal concern.

\subsection{Statement of the Problem}

This study seeks to determine the correlates of the reading interest of the third year high school Chinese students at Singapore International School for the school year 2009-2010. Specifically, it attempts to answer the following questions: 
1) What is the personal profile of the Chinese third year high school respondents with respect to: age, gender, monthly income of parents, academic performance and personal characteristics?

2) What are the external factors that affect the reading interest of the student respondents: people they relate with at home and in school; home environment; and availability of reading materials at home.

3) What are the significant effects and influence of the personal profile of the student respondents and the external factors on the reading interest of the student respondents?

4) What are the highlights of the reading interests of the student respondents according to the following categories: span and extent of interest; specific subject(s) of interest; reading materials preferred; and reading habits?

5) What programs can be proposed to enhance and improve the reading interests of the student respondents?

The study adopts the hypothesis that the following correlates do not significantly affect the reading interest of students in an international school: age, gender, monthly income of parents, academic performance and personal characteristics.

\subsection{Definition of Terms}

The following terms are defined for a better understanding and appreciation of the study:

Reading - This refers to a complex cognitive process of decoding symbols for the purpose of deriving meaning (reading comprehension) and/or constructing meaning.

Interest - This refers to the awareness, attention, and curiosity towards a certain subject, activity, pursuit, people, idea or place.

Reading interest - This refers to the awareness, attention, and curiosity towards a certain subject, activity, pursuit, people, idea or place achieved through reading.

Factors contributing to reading interest - These refer to both personal and environmental aspects that encourage individuals to engage in reading activities.

Personal characteristics - These refer to related specific behaviors exhibited like preferring to be alone or preferring to be with groups and friends.

\subsection{Significance of the Study}

The study will benefit not only the schools and their faculty but especially the students who are primarily the subject of the study. By identifying the correlates that influence and affect the reading interest of the students and the extent of its influence, the schools and their faculty can place the needed emphasis on the correlates that matter against those that do not. This emphasis could be on the type and content of the curriculum that they employ knowing that reading interest is a very important factor in the learning process. They can also create the learning environment in the school that can enhance the reading interest of the students who should be helped in developing the needed behavior and practices.

The students who are the subject of the study will definitely benefit from it and are in fact the primary beneficiaries. The study will surely emphasize to them the importance of developing reading interest in the total learning process and the means for doing it.

\subsection{Scope and Limitations of the Study}

This study focuses on the reading interest of a group of Chinese high school students in a particular international school and attempts to draw some conclusions and findings that hopefully applies in general to all Chinese high school students in that school and in other international schools. Its subject are the Chinese students in third year high school at Singapore International School in Makati City, Philippines. The study is limited to 30 third year high school Chinese students enrolled in the school year 2009-2010.

The study seeks to answer the following questions: Do Chinese students have a particular reading culture? What are the factors that affect their reading interest? Demographic factors are looked into like age, gender, monthly income of parents and personal characteristics. Then it considers external factors that could possibly influence reading interest, such as the people they interact with in school and at home, the home environment and the availability of reading materials.

It also looks into specific reading interests of these high school Chinese students like preferred types of reading materials and reading habits. 


\subsection{Theoretical Framework}

This study is anchored on the theory that interests in general can be individual or situational in orientation. They are distinguished by the former dealing with personal interest and the latter with appropriate environmental settings.

Individual interest is a predisposition to engage in specific objects, events, knowledge, value and positive happenings associated with one's personal interests. The students bring these to their academic experience with some that are similar to classroom learning and some that are incompatible with it. Situational interest, on the other hand, refers to an attraction to a subject or object which is elicited by some environmental stimuli that is generally positive.

Researchers recognize that individual and situational interests may interact. However, the role of either individual or situational interest is particularly important by itself despite the absence of the other. Individual interest helps the individual deal with a subject but situational interest may sustain motivation even in the absence of individual interest. Situational interest may develop over time into individual interest.

This theoretical framework has been applied to the reading interest of our subject respondents. The individual orientation refers to the personal and internal factors while situational orientation refers to the external factors. The former is composed of the independent variables and the latter of the dependent variables.

\subsection{Research Methodology}

This study utilized the descriptive method which involved gathering of data, then analyzing, classifying, tabulating and finally interpreting them Data collection was through a survey questionnaire using as subjects the third year Chinese students for the school year 2009-2010 of the Singapore International School in Makati City, Philippines. Secondary data were also obtained from various sources such as journals, books, articles and papers.

The first part of the survey questionnaire dealt with profile variables like gender, age, monthly incomes of parents and personal characteristics. The second part looked at external factors that contribute to reading interest such as influence of people, availability of reading materials and home environment. The last part took care of respondents' reading interest which included the extent of reading interests, specific subject of reading interests, preferred types of reading materials and specific reading habits.

In presenting, interpreting and analyzing the data, statistical tools and techniques were used. The data were first summarized into frequency and percentage distribution. The percentage was then computed for objective number by dividing the number of responses per category by the total number of respondents. Chi-square was used to determine the relationship between the demographic factors and reading interests.

\section{Review of Related Literature and Studies}

\subsection{Foreign Literature}

\subsubsection{Reading in General and Its Goals}

Reading is a complex cognitive process of decoding symbols with the intention of deriving meaning and/ or constructing meaning. Reading is a means of knowledge acquisition, of communication, and of sharing information and ideas. It is a complex interaction between the text and the reader which is shaped by the reader's prior knowledge, experiences, attitude, and language which is culturally and socially situated. Readers integrate the words they have read into their existing framework of knowledge. Reading is an important tool for people of all societies, allowing them to access information which might have otherwise been unavailable.

The field of visual word recognition studies how people read. Eye tracking is a key technique it uses to study how individuals read a text. The study has revealed that reading is performed by a series of eye fixations on words with some interruptions in between. However, its important finding is that people do not appear to fixate on every word in a text, but instead fixate on some words while filling in the apparent missing information by using context.

Reading is typically an individual activity, although on some occasions a person will read out loud for the benefit of other listeners too. Reading aloud for one's own use or for better comprehension is a form of intrapersonal communication. Before the reintroduction of separated text in the late Middle Ages, the ability to read silently was considered remarkable.

There are multiple principal goals of reading, which are determined by the end the reader has ordained the activity to obtain. The general goal of reading is the acquisition of meaning from the ordered arrangement of symbols. The second goal of reading is "reading to obtain understanding". The reader wishes to receive 
illumination of some discipline or set of facts from the author. The final goal of reading is "reading to obtain information". If a reader is reading a book with the third goal in mind, he may not be as concerned with understanding the arguments and parts of the book and the way these parts relate to the whole.

\subsubsection{Primary Concerns on Reading Interest}

The most important questions raised in literatures on reading interest involve the following: (i) the influence of reading interest on readers' text processing and learning, (ii) the factors that contribute to reading interest, and (iii) the specific processes through which reading interest influences learning.

\subsubsection{Influence of Reading Interest on Text Processing and Learning}

Up to the early 1980's the prevalent view was that proficient readers process and recall the text of what they read according to the hierarchical order of their importance. Starting the 1980's, however, research showed that individual interests and situational interests - rather than hierarchical order of importance --- are what contributed to reading comprehension and learning. It was demonstrated that reading interest affects the type and quality of learning that takes place as it leads to more elaborate and deeper processing of the text read. Furthermore, reading interest affected the degree by which processing strategies benefit memory performance.

\subsubsection{Factors Contributing to Readers' Interest}

Increasing the amount of reading interest of students has become an important educational issue. Researchers indicated that there are certain concepts that can be considered as universal in eliciting individual interests such as death, violence and sex. Other researchers refer to them as emotional interests and contrast them with those complex cognitive structures that contain surprise as element of interest. On the other hand, features that were found to be sources of situational interest are novelty, surprising information, intensity, visual imagery, ease of comprehension, text cohesion and prior knowledge.

Reading interests can also be text based and may depend on certain aspects of the learning environment or the presentation of the educational materials. Hence, reading interest can be promoted by modifying task presentations or curriculum materials that affect the individuals' self- regulation. Educational materials may be presented in more meaningful, challenging or personally relevant contexts that can stimulate interest.

\subsubsection{Processes by Which Interests Influence Learning}

Reading interest is a complex cognitive phenomenon affected by multiple text and reader characteristic. Interest activates text-processing strategies that result in deeper-level processing. The connections that readers may make between new information and their prior knowledge or previous experience increase their interest. Highly concrete and easily imaginable information is more interesting than other types of information. In addition, the informational significance of intensity, novelty, surprise, high personal relevance and character identification meant to elicit interest do not seem to promote the encoding prompted by concrete language and mental imagery.

Another factor that has been associated with interest, reading and increased learning is attention. It is argued that interest associated with automatic attention facilitates learning. It was explained that such attention frees cognitive resources and leads to more efficient processing and better recall of information. Finally, as interest undoubtedly has a strong emotional component, this aspect may play a critical role in how interest influences learning.

Reading interest is influenced by factors that vary from personal to environmental. Such is the nature of adolescence as a phase in an individual's life that is marked by varied and competing priorities on account of the influence of environment. Among the important aspects in the life of an adolescent are his friends which play a major role in his life affecting his likes, dislikes and his social life as a whole. Music may also look insignificant but can occupy an adolescent's interest in life. They can be distracted from reading by music. Playing computer games can also sidetrack young people by diverting their attention and concentration.

\subsection{Related (Foreign) Studies}

\subsubsection{Personal Factor: Gender}

In a study conducted in 2010 in the United States, they found boys trailing girls in reading across states. In reading proficiency boys lag by at least 10 percentage points in some states (Fielding, Wilson \& Anderson, 2005). On the other hand in mathematics, a subject in which girls have historically trailed, the percentages of both genders scoring "proficient" or higher were roughly the same with boys slightly edging the girls and girls even posting stronger scores in some states. It was noted that whether looking at student outcomes at the elementary, middle or high school level, male rates of proficiency were lower than for females across all states studied. 


\subsubsection{Personal Factor: Attitude and Functions for Reading}

Secondary school students' attitudes toward reading can be classified into individual, utilitarian and enjoyment factors. (i) Individual development function relates to the value placed on reading as a means of gaining insight into self, others and/or life in general. (ii) Utilitarian function relates to the value placed on the role of reading for attaining educational or vocational success. (iii) Enjoyment function relates to the pleasures derived from reading. For grade school students, on the other hand, they involve: enjoyment, utility and escape. These are true across a range of cultural settings.

Reports from focus group interviews suggested that factors which facilitated or inhibited adolescents' reading are the result of complex interactions between socio-cultural and peer influences that explore a framework on how literacy practices could facilitate reading development.

For adults, reading is not a substitute for human contact but a motivation for social integration (Hidi \& Harackiewiez, 2000). In their case, three uses prevail for reading: relaxation, keeping abreast and for knowledge. Their reading materials would differ from books, magazines, newspapers, medical handbooks, dictionaries and travel magazines depending on their uses and functions for reading.

\subsubsection{External Factors: Family, Teachers and Others}

Studies showed no positive relationship between the reading habits of parents and their children at grade school. In the case of high school students, however, statistical significance was demonstrated according to the mother's level of education but not according to the father's. Parental socioeconomic background as a whole was found to be weakly linked. However, while parental reading habits did not have a significant relationship, profiles of reading were found to be strongly associated with access to books at home where parents play a big part. Parents of children with high interest provide supportive literary environments by reading to their children more often, watching less television, and having more children's books at home. There were other home factors found significant such as leisure reading, receiving books as gifts, being taken to the library, the age at which parents stopped reading to or with them, and having someone in the home providing encouragement other than parents (Mok \& Cheung, 2004).

Studies showed that children's high interest in reading was found linked to a supportive literacy environment at home and at school (Lewis \& Teals, 2004). For relatively older ones, it showed family factors to be significantly related to leisure reading of avid readers, but reading instructions from schools was not found as a critical factor. These avid readers were found to have some characteristics in common. First, they have regular discussions about books with other readers. Second, they can identify themselves with a community of readers. Third, their parents or other members of the family makes reading a priority over leisure activities. Fourth, variety of reading materials are available to them. Finally, while the enthusiasm of a teacher might be important, school still plays a minor role.

\subsection{Local Studies}

In Eastern culture, a survey of the youth was done in Hong Kong which reported a gender difference in reading interest. More females than males indicated significantly higher frequency in reading a whole book. In China, the government since the start of the 21 st century implemented reading promotional programs to increase awareness on the importance of reading. It had very little impact, however, on achievement oriented high school students.

Several studies and surveys were launched to look at the significant factors that motivate adolescent readers. A national survey data on secondary schools in China was done to look at the role of gender, family and teacher on reading interest with the hope that it would also provide information to parents and teachers on adolescent literacy as a whole.

In Taiwan, Su Yun Chen in 2009 found in his study that adults read non-narrative books more than narrative books. He established for a better understanding of their reading practices, that an association exists between functions of reading and the reading interests of adults. Those who read for relaxation and enjoyment read narrative books on literature, fiction, biography, history and religious books. In contrast, those who read for social conversation topics read non-narrative books on family, health, culture, travel, entertainment, fashion, investment, science books and the best sellers. Taiwanese adults who read basically for knowledge read books on inspiration, religion, investment, consumption and science rather than romance and comics.

\section{Presentation, Analysis, and Interpretation of Data}

This chapter discusses the different correlates that influence the reading interest of the respondents, as follows: (i) respondents' personal profile, (ii) the significant external factors, and (iii) respondents' reading interests. And 
finally, it looks at the application of the data and findings to our subject -- "the Chinese high school students in international schools in general".

\subsection{Personal Profile Variables}

\subsubsection{Distribution of Data}

The data are presented according to their distribution on respondents' profile on gender, age, monthly incomes of parents, academic performance and personal characteristics. Table 1 shows the distribution of the respondents in terms of gender.

Table 1. Gender distribution of respondents

\begin{tabular}{ccc}
\hline Gender & Frequency & Percentage(\%) \\
\hline Male & 17 & 57.00 \\
Female & 13 & 43.00 \\
Total & $\mathbf{3 0}$ & $\mathbf{1 0 0 . 0 0}$ \\
\hline
\end{tabular}

Fifty-seven percent of the respondents are males while forty-three percent are females.

Table 2 shows the age distribution of the respondents.

Table 2. Age distribution of the respondents

\begin{tabular}{|c|c|c|c|c|}
\hline \multirow[b]{2}{*}{ Age (years) } & \multicolumn{2}{|c|}{ Respondents } & \multirow[b]{2}{*}{ Total } & \multirow{2}{*}{$\begin{array}{c}\text { Percentage } \\
\text { (\%) }\end{array}$} \\
\hline & Male & Female & & \\
\hline 14 & & 4 & 4 & 13.33 \\
\hline 15 & 5 & 6 & 11 & 36.67 \\
\hline 16 & 9 & 3 & 12 & 40 \\
\hline $17 \&$ Above & 3 & & 3 & 10 \\
\hline Total & 17 & 13 & 30 & 100.00 \\
\hline
\end{tabular}

The highest frequency in the age profile of the respondents in this study is 16 years old or $40 \%$ of the total number of respondents. This is followed by 36.67 percent of the students who are 15 years old. Thirteen percent of the student respondents are 14 years old while $10 \%$ are 17 years and above.

Table 3 shows the monthly income of the parents of respondents. This refers to the economic status of the parents.

Table 3. Monthly income of parents of respondents

\begin{tabular}{lccc}
\hline & Monthly Incomes & Frequency & Percentage (\%) \\
\hline Below P 25,000 & & 8 & 27.00 \\
P 25,000 - P 49,000 & 17 & 56.00 \\
P 50,000 - P 75,000 & Total & 5 & 17.00 \\
Above P 75,000 & & $\mathbf{3 0}$ & $\mathbf{1 0 0 . 0 0}$ \\
& & & \\
\hline
\end{tabular}

On the economic status of the parents of the respondents, 56 percent of the respondents have parents with monthly income ranging from $\mathrm{P} 50,000$ to $\mathrm{P} 75,000$. In addition, twenty-seven percent of their parents have monthly income from P 25,000 to P 50,000. Lastly, 17 percent of parents of respondents have monthly income above P 75,000. 
Table 4 shows the academic performance of the respondents. This is represented by the grades of the respondents in English in the previous year.

Table 4. Academic performance of the respondents

\begin{tabular}{ccccc}
\hline \multirow{2}{*}{ Grade (\%) } & \multicolumn{2}{c}{ Respondents } & \multirow{2}{*}{ Total } & Percentage (\%) \\
\cline { 2 - 3 } & Male & Female & & \\
\hline $76-80$ & & & & 43.00 \\
$81-85$ & 6 & 7 & 13 & 50.00 \\
$86-90$ & 9 & 6 & 15 & 7.00 \\
Above 90 & 2 & & 2 & $\mathbf{1 0 0 . 0 0}$ \\
Total & $\mathbf{1 7}$ & $\mathbf{1 3}$ & $\mathbf{3 0}$ & \\
\hline
\end{tabular}

Based on the data shown, fifty percent of the respondents had grades in English ranging from 86 to 90 per cent. Forty-three percent of the students had grades from 81-85 percent last year and lastly, only 7 percent had grades above 90 percent.

Table 5 shows the personal characteristics of the respondents.

Table 5. Personal characteristics of the respondents

\begin{tabular}{lllll}
\hline \multirow{2}{*}{ Personal Characteristics } & \multicolumn{2}{l}{ Respondents } & \multirow{2}{*}{ Total } & \multirow{2}{*}{ Percentage (\%) } \\
\cline { 2 - 3 } & Male & Female & & \\
\hline Prefers to be alone & 3 & 3 & 6 & 20.00 \\
Prefers to be with groups/friends & 14 & 10 & 24 & 80.00 \\
Total & $\mathbf{1 7}$ & $\mathbf{1 3}$ & $\mathbf{3 0}$ & $\mathbf{1 0 0 . 0 0}$ \\
\hline
\end{tabular}

Personal characteristics refer to two distinct preferences. These are preference to be alone and preference to be with friends. Of the 30 respondents in this study, 80 percent prefer to be with their groups and friends. These are the extroverts who are essentially outgoing and love to relate with others and a company. On the other hand, 20 per cent would choose to be alone. These are the introverts who are essentially shy and are loners.

\subsubsection{Hypotheses on Personal Profile Variables}

To determine whether the profile variables on age, gender, monthly income of parents, academic performance and personal characteristics relate or not to the reading interests of respondent students, the following hypotheses were individually tested and validated:

1) He gender of the respondents does not relate to their reading interests.

2) The age of the respondents does not relate to their reading interests.

3) The monthly incomes of their parents does not relate to the reading interests of the respondents.

4) The academic performance of the respondents does not relate to their reading interests.

5) The personal characteristics of the respondents do not relate to their reading interests.

Chi-square tests were used for each hypothesis using the following chi-square values: 0.000523 for gender; 0.240008 for age; 0.796566 for monthly income of parents; 0.077626 for academic performance; and 0.011377 for personal characteristics. In all cases, the chi-square values were found in the non-rejection region and the null hypotheses were not rejected. These mean that these personal profile variables do not significantly relate to the reading interests of the student respondents.

\subsection{External Factors}

External factors are composed of the influence of people on respondents, the availability of reading materials at home and the respondents' home environment. Table 6 shows the influence of people on respondents. 
Table 6. Influence of people on respondents

\begin{tabular}{lllll}
\hline \multirow{2}{*}{ People } & \multicolumn{2}{l}{ Weighted Means } & \multirow{2}{*}{ Average Weighted Means } & \multirow{2}{*}{ Interpretation } \\
\cline { 2 - 4 } & Male & Female & & \\
\hline Parents & 1.3 & 0.97 & 1.14 & Very great extent \\
Teacher & 1.36 & 0.87 & 1.12 & Very great extent \\
Classmates & 1.87 & 1.20 & 1.54 & Great extent \\
Friends & 1.93 & 1.13 & 1.53 & Great extent \\
Average Weighted Means & $\mathbf{1 . 6 2}$ & $\mathbf{1 . 0 4}$ & $\mathbf{1 . 3 3}$ & Very great extent \\
\hline
\end{tabular}

The results of the study show that parents (1.14) and teachers (1.12) influence the students to a very great extent while their classmates (1.54) and friends (1.53) affect them only to a great extent, or on a slightly lesser degree. It is to be noted, however, that although both parents and teachers influence them at the same degree, teachers would have more bearing because of their daily interaction with respondents in school. Similarly, classmates would have more influence than friends because of the frequency of their association with respondents.

The availability of reading materials at home, another factor, is shown in Table 7.

Table 7. Availability of reading materials at home

\begin{tabular}{ccccc}
\hline \multirow{2}{*}{ Response } & \multicolumn{2}{c}{ Respondents } & \multirow{2}{*}{ Total } & Percentage (\%) \\
\cline { 2 - 3 } & Male & Female & & 83.00 \\
Yes & 13 & 12 & 25 & 17.00 \\
No & 4 & 1 & 5 & $\mathbf{1 0 0 . 0 0}$ \\
Total & $\mathbf{1 7}$ & $\mathbf{1 3}$ & $\mathbf{3 0}$ & \\
\hline
\end{tabular}

Reading materials at home come in different forms like newspapers and magazines for everyday reading that help them keep abreast. Books at home which could even be books of their parents or siblings are very good sources of information that influence their reading interests.

Table 8 shows to what extent home environment could be conducive to and influence reading.

Table 8. Home environment

\begin{tabular}{ccccc}
\hline \multirow{2}{*}{ Response } & \multicolumn{2}{c}{ Respondents } & Total & Percentage (\%) \\
\cline { 2 - 3 } & Male & Female & & 70.00 \\
Yes & 12 & 9 & 9 & 30.00 \\
No & 5 & 4 & $\mathbf{3 0}$ & $\mathbf{1 0 0 . 0 0}$ \\
Total & $\mathbf{1 7}$ & $\mathbf{1 3}$ &
\end{tabular}

Seventy percent of the respondents say that their home environment is generally helpful in creating an atmosphere for reading while thirty percent answer in the negative. Home environment of the students can be of different settings. It can be a quiet home where noise is minimal or one where there is music, radio or television. Different individuals respond to different home environments.

\subsection{Reading Interest Data}

The following were also considered on the reading interest: (i) the extent of interest in reading, (ii) specific reading interests, (iii) types of reading materials and (iv)specific reading habits.

Table 9 shows the extent of interest of respondents in reading. 
Table 9. Extent of interest in reading

\begin{tabular}{|c|c|c|c|c|}
\hline \multirow{2}{*}{ Extent of Interest } & \multicolumn{2}{|c|}{ Respondents } & \multirow{2}{*}{ Total } & \multirow{2}{*}{ Percentage $(\%)$} \\
\hline & Male & Female & & \\
\hline Very Much & & 6 & 6 & 20.00 \\
\hline Much & 9 & 5 & 14 & 47.00 \\
\hline Not Much & 8 & 2 & 10 & 33.00 \\
\hline \multicolumn{5}{|l|}{ Not at All } \\
\hline Total & 17 & 13 & 30 & 100.00 \\
\hline
\end{tabular}

From these data, the difference in the number of males and females interested from very much and much in reading is not large. In other words, gender or whether one is a male or female is not a significant issue in extent of reading interest.

Table 10 shows the specific reading interests of the respondents.

Table 10. Specific reading interests

\begin{tabular}{cccccc}
\hline \multirow{2}{*}{ Reading Materials } & \multicolumn{2}{c}{ Respondents } & \multirow{2}{*}{ Total } & \multirow{2}{*}{ Ranking } \\
\cline { 2 - 3 } & Male & Female & & 10 & 10.5 \\
Adventure & 6 & 4 & 11 & 7.5 \\
Historical & 5 & 6 & 15 & 3 \\
Fantasy & 6 & 9 & 10 & 10.5 \\
Horror & 5 & 5 & 14 & 4.5 \\
Humor & 8 & 6 & 10 & 10.5 \\
Mystery & 6 & 4 & 10 & 10.5 \\
Romance & 1 & 9 & 13 & 6 \\
Science Fiction & 6 & 7 & 16 & 2 \\
Sports & 13 & 3 & 11 & 7.5 \\
Health & 5 & 6 & 17 & 1 \\
Music & 9 & 8 & 7 & 13.5 \\
Television Materials & 5 & 2 & 14 & 4.5 \\
Movie Materials & 9 & 5 & 7 & 13.5 \\
Biographies & 3 & 4 & & \\
\hline
\end{tabular}

Among the types of reading materials, music ranked number (1), followed by sports (2) and fantasy (3) and the last rank was shared by television and biographies (13.5). The noted difference in the reading preference of the male and female students is the preference of male for sports and romance for female. As a whole, however, the differences between the male and female students reading preferences are not well established.

Table 11 shows the types of reading materials of the student respondents.

Table 11. Types of reading materials

\begin{tabular}{cccccc}
\hline \multirow{2}{*}{ Types of Reading Materials } & \multicolumn{2}{c}{ Respondents } & \multirow{2}{*}{ Total } & \multirow{2}{*}{ Ranking } \\
\cline { 2 - 3 } & Male & Female & & 18 & 2 \\
Magazines & 9 & 9 & 7 & 3 \\
Newspapers & 5 & 2 & 23 & 1 \\
Books & 12 & 11 & 5 & 4 \\
Comic Books & 1 & 4 & & \\
\hline
\end{tabular}


Both male and female prefer to read books but take note of the last preference of male for comic books and female for newspapers. As a whole, however, comic books ranked as last preference.

Table 12 shows the specific reading habits of the respondents.

Table 12. Specific reading habits

\begin{tabular}{lllll}
\hline \multirow{2}{*}{ Reading Habits } & \multicolumn{2}{l}{ Respondents } & \multirow{2}{*}{ Total } & \multirow{2}{*}{ Percentage (\%) } \\
\cline { 2 - 4 } & Male & Female & & \\
\hline Reading during free time & 9 & 8 & 17 & 57.00 \\
Finding time to read & 4 & 3 & 7 & 23.00 \\
Reading materials required in school only & 4 & 2 & 6 & 20.00 \\
Total & $\mathbf{1 7}$ & $\mathbf{1 3}$ & $\mathbf{3 0}$ & $\mathbf{1 0 0 . 0 0}$ \\
\hline
\end{tabular}

These show that 57 percent of the respondents read during their free time while 23 percent really find time to read. The 20 percent read only materials that are required in school. It is good to note, however, that on the whole about 80 percent of the respondents read on their own given the opportunity or deliberately because of their interest in reading.

\subsection{Reading Program Proposals}

Given the challenges they face, young students should equip themselves with basic skills and competencies which include reading, writing and speaking. The benefits of reading competence cannot be underestimated. It should be developed and cultivated at an early age. It develops ones self- confidence, widens his horizon and enhances his opportunity for a successful career. The following reading programs are proposed for our Chinese students, which we call the "Unlocking Reading Program" and the "Competitive Reading Program":

\subsubsection{Program A: "Unlocking Reading” Program}

Many students struggle not only with understanding the English words but also vocalizing and pronouncing the words and using them in the context of their meanings. This program is proposed which come in three modules.

Part 1: Exposure to Common Conversational Words - This module runs for two sessions each week for two weeks. The teacher gives out common conversational words which the students pronounce aloud as a form of "decoding" them.

Part 2: Understanding the Meaning of Common Conversational Words - This runs for 3 sessions of 45 minutes per week for two weeks. The teacher presents common conversational words, explain their meanings and demonstrate them in different ways.

Part 3: Using Common Conversational Words -This is a continuation of Part 2. The teacher after demonstrating the conversational words in different ways asks the students to use them in their own way.

\subsubsection{Program B: “Competitive Reading” Program}

This challenges the teacher to develop the interest of the student in reading to be competitive. This comes in three parts.

Part 1: Listing of Titles - The teacher every two weeks puts up the titles of two books that are "highly recommended" for reading. This is done continuously for the duration of the program.

Part 2: Borrowing and Reading a Book - The student selects a book from the reading list which he is expected to read for two weeks. He signs up in a "reading track card". The teacher is expected to have read the book too.

Part 3: Conferencing with the Teacher - After reading the book for two weeks, the student and teacher schedules a meeting/conference where the student discusses the book and shares his own ideas and reactions about the book. The student is encouraged to ask questions. This is approximately for 25 minutes. The teacher and the student signs up in the "reading track card."

\subsection{Application of Data and Findings to Our Subject}

In determining the size of the sample that we used in the survey, which is thirty third year Chinese high school students, we used the criterion (Coolican, 1992) that proposes this sample size if the experimental independent variable can be safely assumed to have similar effect on most people. We also utilized the theoretical framework 
that reading interests in general can be individual and situational in orientation. On individual orientation, we assumed that since our subjects have the same cultural setting, being all Chinese, they would have the same individual orientation in their reading interest. On the situational orientation, their environmental stimuli would be more or less of the same level and category given the same kind of families and the same kind of school, an international school.

We therefore adopt the hypothesis that our data and findings, together with our conclusions and recommendations below, would apply in general to all Chinese high school students in international schools.

\section{Summary of Findings, Conclusions and Recommendations}

\subsection{Summary of Findings}

The summary of the findings from the data gathered and validated are as follows:

\subsubsection{On the Profile Variables}

1) Gender of Respondents - There are more male than female respondents. Fifty-seven percent are males and forty-three percent female.

2) Age of Respondents - Forty percent of the total number of respondents are 16 years old and only ten per cent are 17 years old and above.

3) Monthly Income of Parents - Fifty-six percent of the respondents have parents with monthly income ranging from P 50,000 to P 75,000.

4) Academic Performance - Fifty percent of the respondents have grades in English ranging from $86 \%$ to $90 \%$ in the previous year.

5) Personal Characteristics - Eighty percent of the respondents prefer to be with their groups and friends rather than be alone.

\subsubsection{On the External Factors}

1) Influence of People on Respondents - The influence of parents on respondents rated a weighted mean of 1.14 while the teachers influence rated an average mean value equal to 1.12 .

2) Availability of Reading Materials at Home - Eighty-three percent of the respondents agree that they have reading materials at home while seventeen percent says they do not have.

3) Home Environment-Seventy percent of the students agree that their home environment is generally conducive to reading while thirty percent disagreed.

4.1.3 On the Reading Interests of the Respondents

1) Extent of Reading Interest - Sixty-seven percent of the respondents are interested in reading.

2) Specific Reading Interest - Music ranked first (17) in the respondents' reading interest followed by sports (16) and fantasy(15).

3) Preferred Types of Reading Materials - Both male (12) and female (11) respondents prefer to read books. This ranked first.

4) Specific Reading Habits - Fifty-seven percent of the respondents read during their free time.

4.1.4 On the Reading Hypotheses Validation

To determine whether gender, age, monthly income of parents, academic performance and personal characteristics significantly relate to the reading interests of the respondents, the study used the chi-square test. The computed chi-square values are as follows: 0.000523 for gender, 0.240008 for age, 0.796566 for monthly income of parents, 0.077626 for academic performance, and 0.011377 for personal characteristics.

\subsection{Conclusions}

\subsubsection{With Respect to the Profile Variables}

There are more males than females in this study and respondents are young students. They come from average income families. In terms of academic performance, the respondents belong to the average and high average categories in their English classes. Lastly, most of the respondents prefer to be with their groups and friends rather than be alone.

\subsubsection{With Respect to the External Factors}

Parents and teachers influence the respondents to a very great extent while their classmates and friends affect 
them only to a great extent or on a slightly lesser degree. Majority of the respondents agree that they have reading materials at home and that their home environment is generally conducive to reading.

\subsubsection{With Respect to the Reading Interests of Respondents}

Majority of the respondents are basically interested in reading. The male respondents show preference for sports while female respondents choose romance. Both male and female prefer music. They both prefer to read books than other reading materials and majority read during their free time.

\subsubsection{With Respect to Reading Hypotheses Validation}

To determine whether gender, age, monthly incomes of parents, academic performance and personal characteristics significantly relate to the reading interests of the respondents, the chi-square test was used. All the computed chi-square values are found in the non-rejection region. Therefore, gender, age, monthly income of parents, academic performance, and personal characteristics do not significantly relate to or affect the reading interests of the respondents.

\subsection{Recommendations}

Based on these reported findings and conclusions, this study submits the following recommendations:

1) That young students of all ages be encouraged to cultivate a desire for and interest in reading regardless of gender, age, economic status, and uniqueness in terms of personal characteristics;

2) That a campaign for love of reading be undertaken by school authorities, not to mention the support from the families of the students, to have more books at home and develop a home environment that provides a positive atmosphere for reading;

3) That provisions for developing good reading habits be part of the English curriculum of schools to reinforce a reading culture among the students;

4) That student organizations with emphasis on reading be organized and managed that provide structures for systematic monitoring of students' progress; and

5) That further studies be conducted, such as:

a) A study of the reading programs in other Chinese schools.

b) A study of the reading problems encountered by high school students.

c) A study on reading strategies for optimum learning.

\section{References}

Atkinson. (2009, June). Cathy. School Psychology International, 30(3), 237.

Chen, S. Y. (2009, Summer). Reading Improvement. Chula Vista, 46(2), 108-117.

Erik, W. (2010, March 31). Robelen. Education Week, 29(27), 10.

Fielding, L. G., Wilson, P. T., \& Anderson, R. C. (2005). A new focus on free reading: The role of trade books in reading instruction. In T. Raphael (Ed.), The contexts of school-based literacy (pp. 149-160). New York: Random House.

Gambell, T., \& Hunter, D. (2000). Surveying gender differences in Canadian school literacy. Journal of Curriculum Studies, 32(5), 689-719. http://dx.doi.org/10.1080/00220270050116941

Greaney, V., \& Neuman, S. B. (2001). The functions of reading: A cross-cultural perspectives. Reading Research Quarterly, 25(3), 172-195. http://dx.doi.org/10.2307/748001

Hidi, S., \& Harackiewiez, J. M. (2000). Motivating the Academically Unmotivated: A Critical Issue for the 21st Century. Review of Educational Research, 70(2), 151-179.

Hoffman, L., \& Haussler, P. (1998). An Intervention Project Promoting Girls' and Boys' Interest in Physics. In L. Hoffman, A. Krapp, K. A. Renninger, \& J. B. Kiel (Eds.), Interest and Learning: Proceedings of the Seeon Conference on Interest and Gender. Germany: Institute for Science Education (IPN).

Kintsch, W. (1980). Learning from Texts, Levels of Comprehension, or Why Anyone Would Read a Story Anyway. Poetics, 9, 87-98. http://dx.doi.org/10.1016/0304-422X(80)90013-3

Kirsch, \& Guthrie. (2001). Adults reading practices for work and leisure. Adult Education Quarterly, 34(4), 213-232. http://dx.doi.org/10.1177/0001848184034004003

Kirsch, I., de Jong, J., Lafontaine, D., McQueen, J., Mendelovits, J., \& Monseur, C. (2002). Reading for change: 
Performance and engagement across countries. Paris: Organisation for Economic Co-operation and Development.

Lewis, R., \& Teals, W. H. (2004). Another look at secondary school students' attitudes toward reading. Journal of Reading Behavior, 12, 187-201.

Lituanas, P. M., Jacobs, G. M., \& Renandya, W. A. (2001). An investigation of extensive reading with remedial students in a Philippines secondary school. SEAMEO Regional Language Center (RELC), 30 Orange Grove Road, Singapore 258352, Singapore.

Manguel, A. (2000). A History of Reading. New York: Viking.

McDaniel, M. A., Finstad, K., Waddill, P. J., \& Bourg, T. (2000). The Effects of Text-Based Interest on Attention $\begin{array}{llll}\text { and Recall. Journal of Educational Psychology, 92(3), 492-502. } & \text {. }\end{array}$ http://dx.doi.org/10.1037/0022-0663.92.3.492

Moffitt, M. A. S., \& Wartella, E. (2004). Youth and reading: A survey of leisure reading pursuits of female and male adolescents. Reading Research and Instruction, 31(2), 1-17. http://dx.doi.org/10.1080/19388079209558075

Mok, J., \& Cheung, S. (2004). Book reading culture of youth in Hong Kong. Hong Kong: The Hong Kong Federation of Youth Groups.

Morrow, L. M. (2004). Home and school correlates of early interest in literature. Journal of Educational Research, 76(4), 221-230.

Sadoski, M. (2001). Resolving the Effects of Concreteness on Interest, Comprehension, and Learning Important Ideas from Text. Educational Psychology Review, 13(3). http://dx.doi.org/10.1023/A:1016675822931

Schank, R. C. (2000). Interestingness: Controlling Inferences. Artificial Intelligence, 12, 273-297. http://dx.doi.org/10.1016/0004-3702(79)90009-2

Schraw, G., \& Dennison, R. S. (2004). The Effect of Reader Purpose on Interest and Recall. Journal of Reading Behavior, 26(1), 1-18.

Schraw, G., Bruning, R., \& Svoboda, C. (2005). Sources of Situational Interest. Journal of Reading Behavior, 27, 1-17. http://dx.doi.org/10.1023/A:1016619705184

Schraw, G., Flowerday, T., \& Lehman, S. (2001). Increasing Situation Interest in the Classroom. Educational Psychology Review, 13(3), 211-224.

Steinberg, H. (2002). Social integration as the source of motivation to read among adults. Journal of Reading, 22(8), 745-747.

Strommen, L. T., \& Mates, B. F. (2004). Learning to love reading: Interviews with older children and teens. Journal of Adolescent \& Adult Literacy, 48(3), 188-200. http://dx.doi.org/10.1598/JAAL.48.3.1 